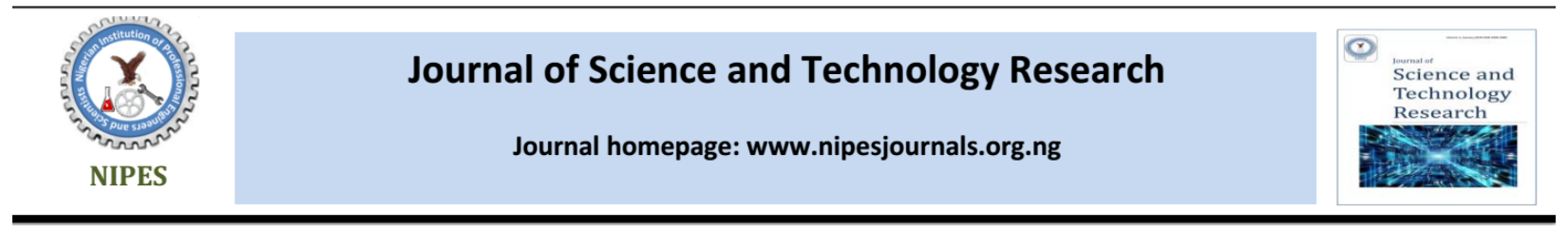

\title{
Design and Fabrication of Portable Weld Residual Stress Measuring Device using MBN Principle
}

\author{
C.E. Etin-Osa ${ }^{1 *}$, J. I. Achebo ${ }^{2}$ and K. O. Obahiagbon ${ }^{3}$ \\ ${ }^{1,2}$ Department of Production Engineering, University of Benin, Edo State Nigeria \\ ${ }^{3}$ Department of Chemical Engineering, University of Benin, Edo State Nigeria \\ Email: etinosa.eruogun@uniben.edu
}

\section{Article Info}

Received 04 June 2020

Revised 29 June 2020

Accepted 01 July 2020

Available online 31 August 2020

Keywords: Labview, Simufact, Residual stress, Barkhausen,

Amplifer, magnet, weld

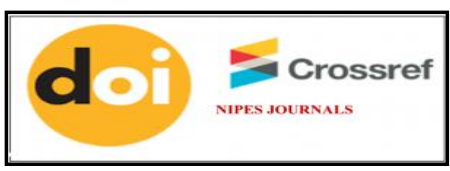

https://doi.org/10.37933/nipes/2.3.2020.8

https://nipesjournals.org.ng (c) 2020 NIPES Pub. All rights reserved

\begin{abstract}
Residual stress are stresses that remains in an engineering material, especially metallic materials, after the original applied load has been removed. Its measurement will help reveal areas in fabricated materials highly stressed. This paper presents a design of a portable residual stress measuring device based on the magnetic barkhausen noise principle. This was achieved by using two permanent magnets, a pickup coil, amplifier and an analogue to digital converter to create the hardware. The software was designed using LabVIEW 2019. After fabrication, measuring experiments on mild steel materials were conducted and the results obtained from using the device for measurement were compared to simulated values (Simufact.Weld 6.0) CAD software. Comparing its results with that obtained from Simulation showed an $R^{2}$ value of $77.47 \%$ with a strong correlation of 0.831 and a $P$-value of 0.0071 which was less than the 0.05 alpha level taken. This device can be adopted in weld residual stress measurement by artisans and roadside welders for effective minimization of residual stress and failures associated with it.
\end{abstract}

\section{Introduction}

Nearly all infrastructural disasters recorded in Nigeria are manmade [1]. Technical and mechanical failures of constructed and fabricated materials which pose danger to live and property and, in some cases, claimed lives is on the increase. These failures are seen in a vast range of products including collapsed buildings, broken bill board stands, water storage stand failure, toppling trailer, refurbished automobile part failure, even house hold appliances [2]. Most fabrication works in Nigeria are carried out by road-side artisans who are ignorant of the danger posed by residual stress. Residual stress are stresses that remains in an engineering material, especially metallic materials, after the original applied load has been removed [3] and [4]. These stresses are usually introduced into the materials, during manufacturing, fabrication or during machine operation [5]. Residual stresses are measured using destructive, semi-destructive or non-destructive methods [6], the finite element method (FEM) are seldom used for residual stress measurement because it is 
time consuming. Manufactured and fabricated components are best measured using the nondestructive method as finished products will not be destroyed in the process. X-ray diffraction technique is the most popular method of non-destructive residual stress measurement, and measurement is often carried out in the lab one major drawback is that the specimen is limited by the size of the device x-ray chamber. In Nigeria, these measuring devices are hard to find and very expensive to purchase by researchers and fabricator artisans. Most of the structural failures experienced in Nigeria, can be minimized or prevented if an affordable residual stress safety device can introduce to the Nigerian fabrication industries, since more ferromagnetic (mostly iron and its alloys) materials are mostly used for welding. Residual stress measurement will help reveal areas in fabricated materials highly stressed, it also aid designers in estimating good shelf life and also minimizes "unexpected" failures and the unpleasant situations associated with them.

This study presents a design of a portable residual stress measuring device, based on the magnetic barkhausen noise, that can be used as an alternative to X-ray diffraction method for ferromagnetic materials and also to demonstrate its application in welding as a promising weld residual stress measuring device which can produce a fast measurement indoor and outdoor.

\section{Materials and Methods}

This device was designed based on the magnetic barkhausen noise principle. Permanent magnets, search coil (also known as pickup coil), mini amplifier (amp), analogue to digital converter (ADC) and a software to analyze the data (Labview), were the materials used for design.

Two identical strong rare earth neodymium iron boron (NdFeB) magnet (N52) were used for the magnetic sensor. The magnet is a cylinder with diameter $10 \mathrm{~mm}$ and height of $20 \mathrm{~mm}$. These magnets are brittle, therefore, extreme care was taken to avoid damaging it by not allowing it smash together due to its attractive power.

Equation (1) given by [7] help us understand the formation of magnetic domains as it occurs because of a minimization contest of the five basic energies involved in ferromagnetism:

$$
E=E_{\text {exchange }}+E_{\text {magnetostatic }}+E_{\text {magnetocrystalline }}+E_{\text {magnetoelastic }}+E_{\text {wall }}
$$

The penetration depth of magnet on ferromagnetic material can be calculated (estimate) using the formula obtained from [8], presented in Equation (2).

$$
\delta=1 / \sqrt{ }(\pi \mu \sigma f)
$$

Where $\delta$ represents the penetration depth, $\mu$ denotes the magnetic permeability, $\sigma$ represents the electrical conductivity while $f$ represents the frequency of the alternating magnetic field.

In other to determine the depth of magnetic influence on our material, the experimental (crude method) means was adopted. Firstly, we started by collecting some iron dust from Engineering Laboratory (ELA), University of Benin. We considered six (6) categories of specimen thicknesses for the experiment namely: $1 \mathrm{~mm}$ plate, $2 \mathrm{~mm}$ plate, $3 \mathrm{~mm}$ plate, $4 \mathrm{~mm}$ plate, $5 \mathrm{~mm}$ plate and $6 \mathrm{~mm}$ plate which are all ferromagnetic mild steel materials. 


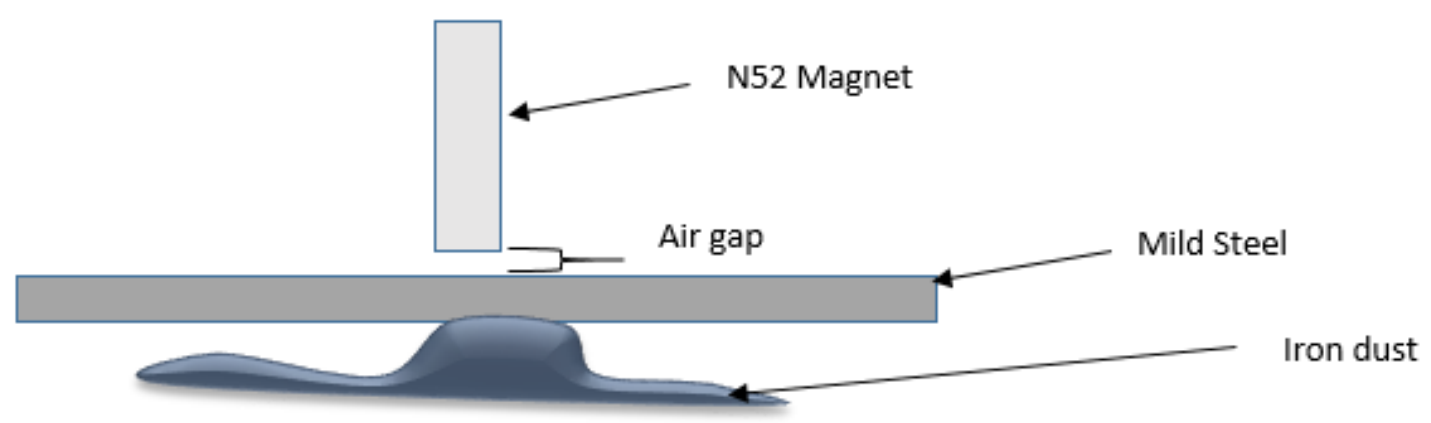

Figure 1: Illustration of the depth of penetration experiment

Air gap of $2 \mathrm{~mm}$ between the magnet and the plates was created, with the magnet placed on the plate while the plate was placed of the iron dust as sketched in Figure 1. Table 1 gives the summary results observed from the experiment.

Table 1. Depth of penetration

\begin{tabular}{|l|l|l|l|l|l|}
\hline \multirow{2}{*}{ Mild steel Plate } & \multicolumn{3}{|l|}{$\begin{array}{l}\text { Magnetic } \\
\text { observed }\end{array}$} \\
\cline { 2 - 7 } & N & VL & L & S & VS \\
\hline $1 \mathrm{~mm}$ & & & & $\sqrt{ }$ & \\
\hline $2 \mathrm{~mm}$ & & & $\sqrt{ }$ & & \\
\hline $3 \mathrm{~mm}$ & & $\sqrt{ }$ & & & \\
\hline $4 \mathrm{~mm}$ & $\sqrt{ }$ & & & & \\
\hline $5 \mathrm{~mm}$ & $\sqrt{ }$ & & & & \\
\hline $6 \mathrm{~mm}$ & $\sqrt{ }$ & & & & \\
\hline
\end{tabular}

Where $\mathrm{N}$ represent no visible effect on iron dust magnetization, VL denotes very low magnetization effect on iron dust, $\mathrm{L}$ means low magnetization effect on iron dust, $\mathrm{S}$ represent strong magnetization effect on iron dust and VS means very strong magnetization effect on iron dust.

The search coil is a solenoid fitted with two permanent neodymium magnets, the induction coil sensor has a transfer function of $V=f(B)$ resulting from the Faraday's law of induction where

$$
V=-N \frac{d \Phi}{d t}=-N A \frac{d B}{d t}=-\mu N A \frac{d H}{d t}
$$

The aim of the coil design is to obtain a strong magnetic signal using the faradays law of induction, which from proof of principle, the output signal, $\mathrm{V}$, of a coil sensor depends on the rate of change of flux density, $\mathrm{dB} / \mathrm{dt}$. It was observed that the induced voltage $\mathrm{V}$ from an alternating magnetic field, is affected by the core material where the permeability $(\mu)$ is presented in equation 3 .

In the coil design, coil thickness of $1 \mathrm{~mm}$ was used due to limited technology in handling the previous $0.01,0.02$ and $0.03 \mathrm{~mm}$ coil earlier purchased for the project, as the $0.01-0.03 \mathrm{~mm}$ coil wire kept breaking during winding. [10] Suggested smaller wire diameter for better results, a greater number of turns of wire in the coil also contributes to greater inductance; while a fewer 
numbers of turns results in less inductance. The pickup coil had a winding of 2500 turns which was achieved by using a locally made winder. Figure 2 shows the completed pickup coil.

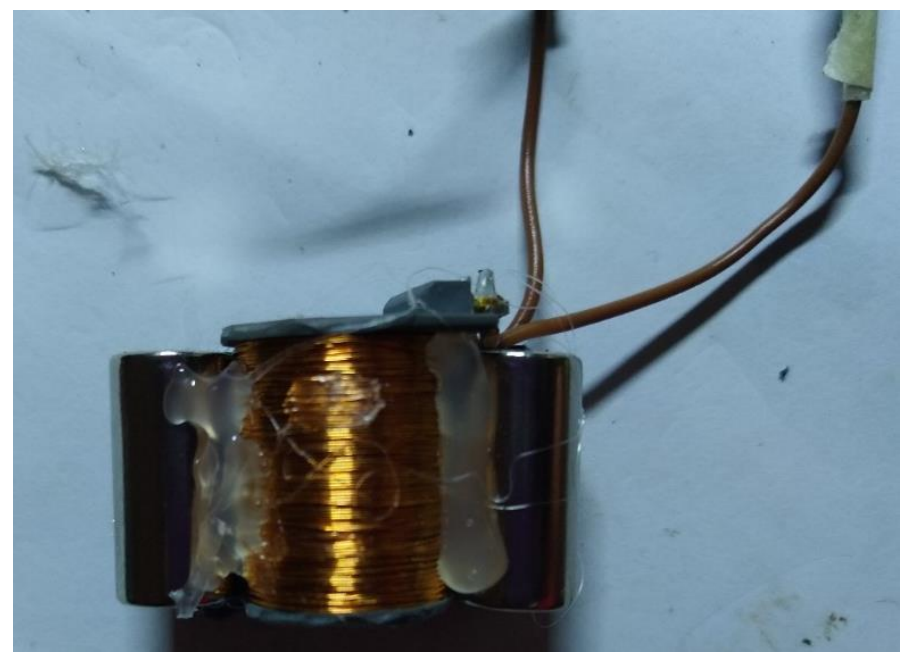

Figure 2: pickup coil with two N52 magnets fixed in place

The signal generated due to domain flipping in the ferromagnetic material picked-up by the search coil came out very faint, therefore, it was boosted/magnified with the PAM8403. PAM8403, 3W, class-D audio amplifier.

To analyze the signal generated, the Arduino Nano with Atmega328p processor was used.

The resolution provided by the Arduino Nano ADC is 10 bits, the ADS1115 which provides a 16bit resolution and communicates via I2C interface was used to enhance the sensor for better resolution. In summary, the ADS1115 was used as the primary analog to digital converter (slave), connected to the Arduino Nano (Master).

In the design presented in Figure 3, two of N52 magnets where employed with their dipole vertically opposite. The reason for that is aimed at eliminating trapping/pinning of domain walls that results whenever the magnet glides across the surface of the specimen, it is expected that the domain wall should flip due to the diploe directions which help reveal more details about the nature of the internal material.

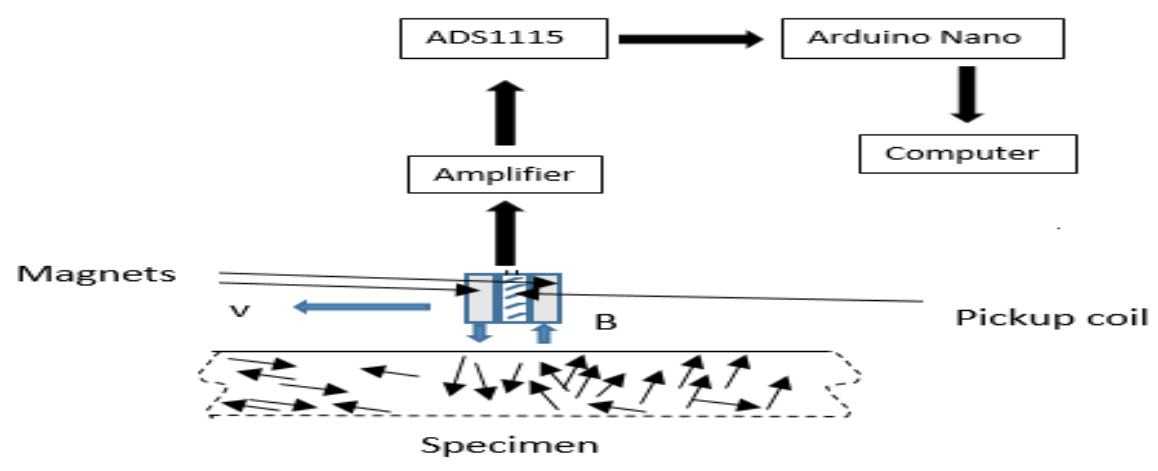

Figure 3: Schematic image of barkhausen sensor, measuring specimen by moving across specimen surface with a velocity $\mathrm{V}$ 
The two wires from the coil were connected to the PAM8403 mini amp, the output of PAM8403 was connected to the ADS1115 ADC. The ADC was connected to the nano, then to the computer. To establish communication between the nano and the ADC, the following connections where made. Note $\mathrm{V}_{\mathrm{DD}}=$ positive voltage input to $\mathrm{ADS} 1115, \mathrm{GRD}=$ ground or the negative voltage connection, $\mathrm{SCL}=$ serial clock line, $\mathrm{SDA}=$ serial data address

$\mathrm{V}_{\mathrm{DD}}$ from the $\mathrm{ADC}$ was connected to the $5 \mathrm{v}$ pin on the Nano.

GRD from the ADC was connected to the GRD on the Nano.

SCL from the ADC was connected to A5 on the Nano.

Lastly, SDA from the ADC was connected to A4 on the Nano.

For compatibility, the pickup coil, amp and ADC were fitted in a small rectangular box designed to be handy and have four mini tyres at the bottom to enable dynamic motion across the surface of the sample.

Orthographic view for our sensor casing is shown in Figure 4, HP laptop power pack of $50 \times 30 \times 125 \mathrm{~mm}$ presented in Figure 5 was recycled, its internal components discarded and the casing used to house our magnets, coil, ADS1115 and Arduino board. The four (4) tyres fitted to the device, had an outer diameter of $1 \mathrm{~mm}$. An area of $880 \mathrm{~mm}^{2}$ was created at the base of the casing. This area serve as a vacuum through which the sensor can interact with the specimen during measurement. picture of the fabricated device with its connectivity is presented in Figure 6

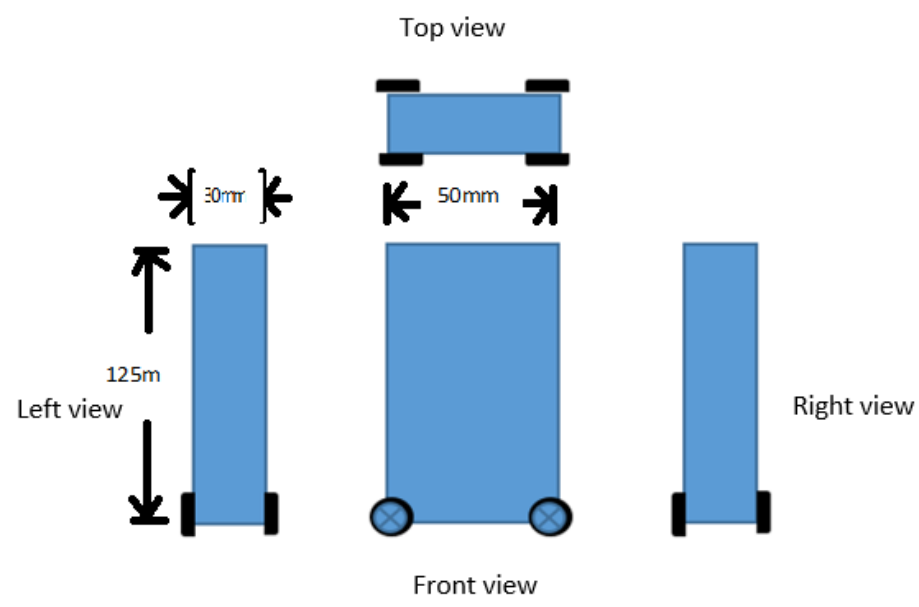

Figure 4: Orthographic view for our sensor casing 
C.E Etin-osa et al. / NIPES Journal of Science and Technology Research 2(3) 2020 pp. $70-84$

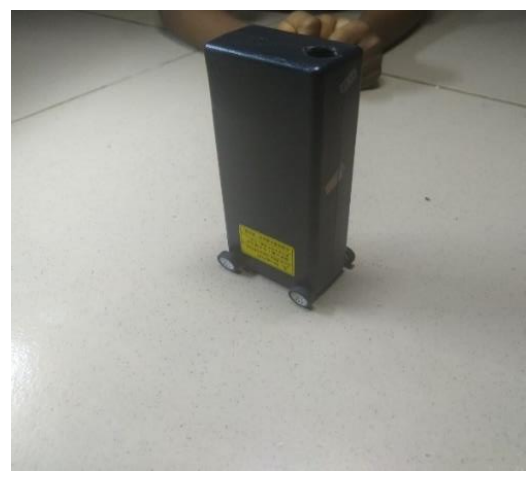

Figure 5: Recycled laptop power pack fitted with tyres

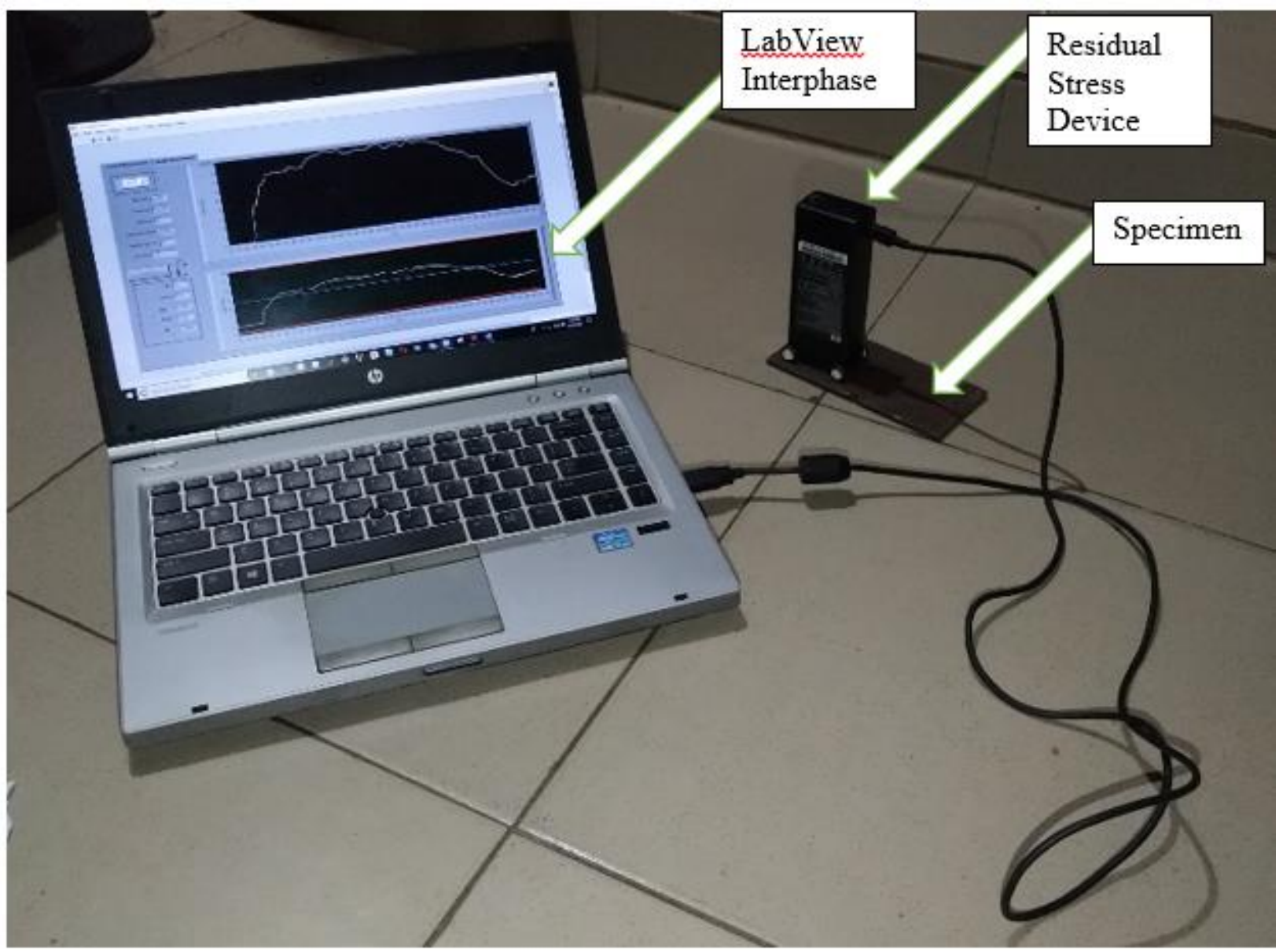

Figure 6: device measurement connection 
LabVIEW 2019 was used to analyze the data obtained. The user interface in Figure 7 was designed by using sets of tools and objects. After building the front panel, we added code using graphical representations of functions to control the front panel objects. The graphical code, also known as $\mathrm{G}$ code or block diagram code was added, to the block diagram which resembles a flowchart. The block diagram, front panel, and graphical representations of code compose a VI.

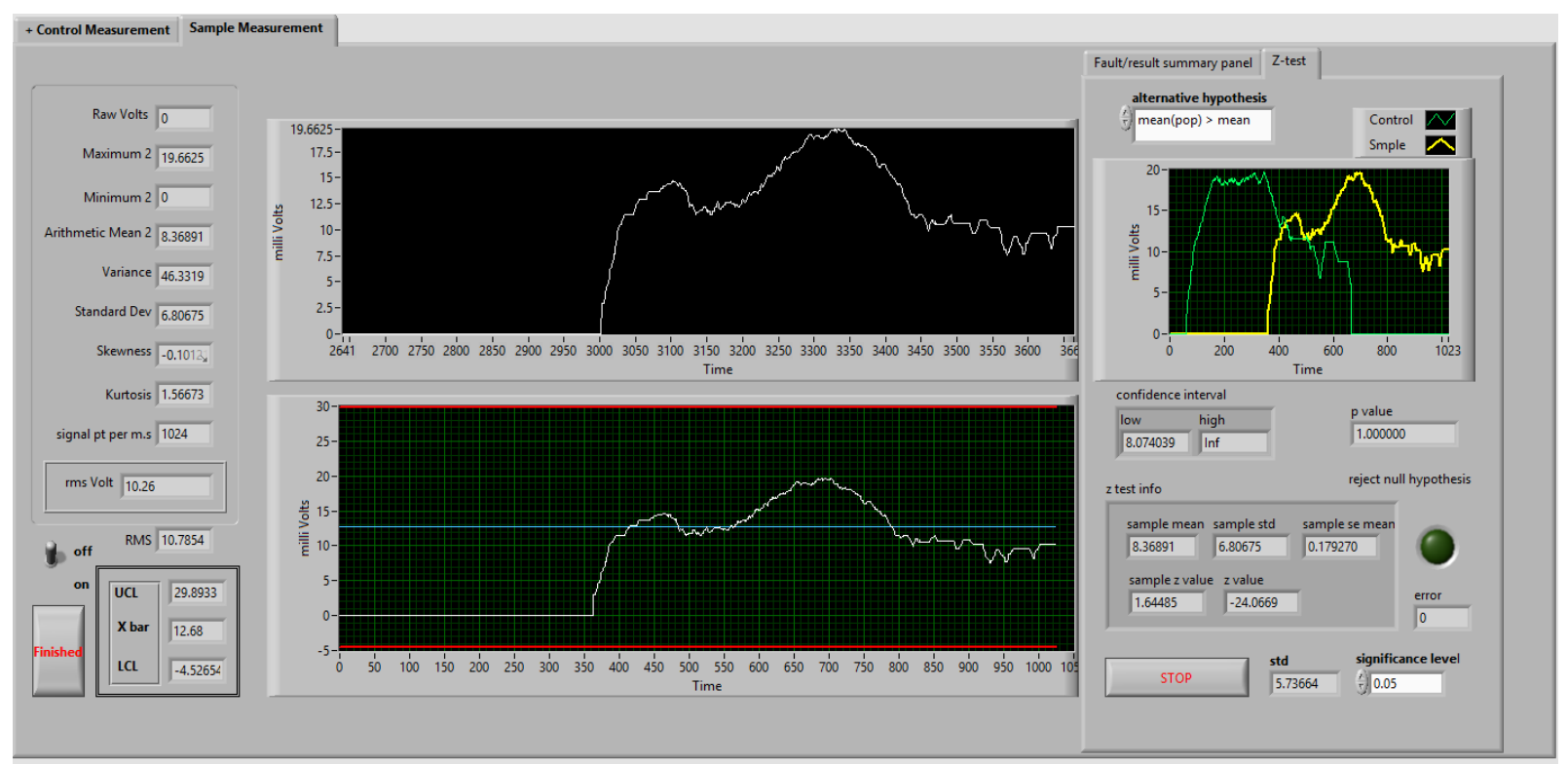

Figure 7: LabVIEW GUI for the Magnetic device

To validate our result, comparison between results obtained between repeated experimental weld reading for consistency and simulated values obtained using simufact.weld 6.0 software in Figure 8 were conducted, using weld parameter in Table 2 .

Table 2: Weld Process Parameter

\begin{tabular}{|l|l|l|l|}
\hline Sample & Current (Amp) & Voltage (V) & Weld Speed (mm/s) \\
\hline B11 & 120 & 62 & 2.497 \\
\hline
\end{tabular}

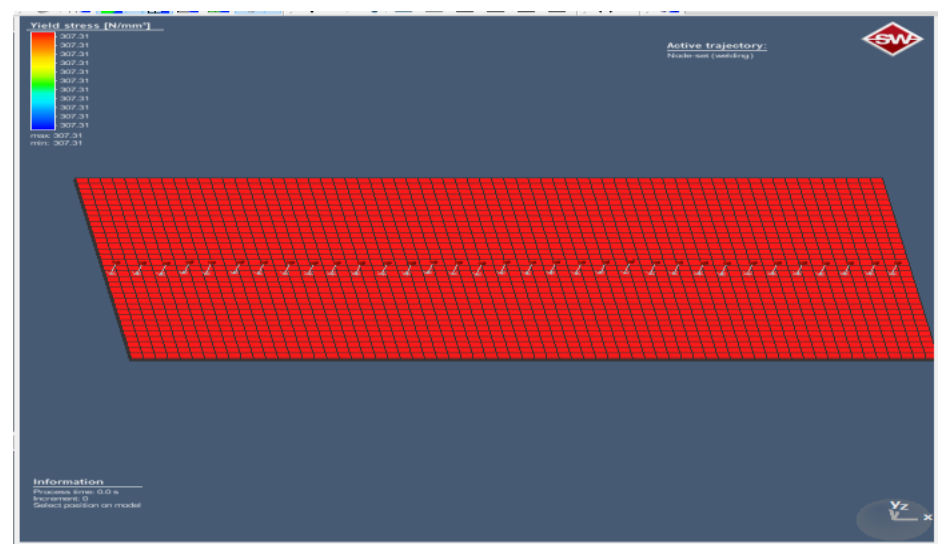

Figure 8: Yield stresses for specimen $\mathrm{B}_{11}$ before weld 
Thirty seven points were selected from the simulated specimen as shown in Figure 8. The yield stresses across the material before weld is given as $307.3 \mathrm{~N} / \mathrm{mm}^{2}$.

\section{Results and Discussion}

\subsection{Comparison between device results and Simufact.weld 6.0}

In this study, five (5) repeated readings were obtained for $\mathrm{B}_{11}$ using the magnetic device. The wave form chart readings for $\mathrm{B}_{11}$ was exported to Excel and Minitab for analysis. One out of the five readings was compared with result obtained from the simulated welded component in Simufat.weld.

The results obtained from the above experiment for five (5) repeated readings and from simufact.weld are presented in Table 3 , for specimen $\mathrm{B}_{11}$. Thirty seven (37) signals were obtained from the specimen for one experimental run, the five repeated measurements were compared amongst themselves for any significant variability. The signals for each of the repeated experiment against time are presented in Figure 9 - 13. Figure 14 shows the combine series time plot for the five (5) of specimen $\mathrm{B}_{11}$, while Table 3 present the Magnetic Device reading for specimen $\mathrm{B}_{11}$.

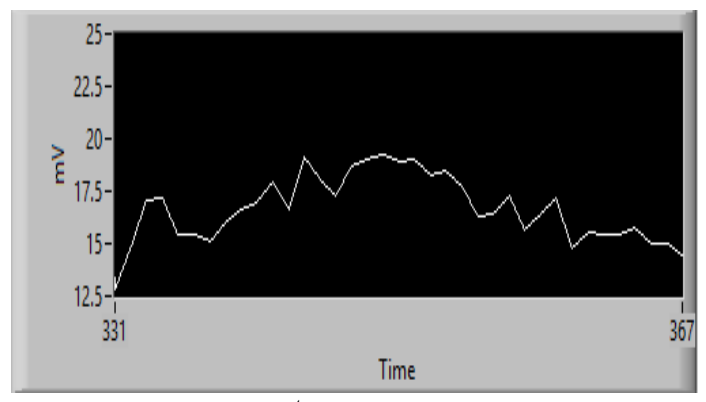

Figure 9: $1^{\text {st }}$ reading from $\mathrm{B} 11$

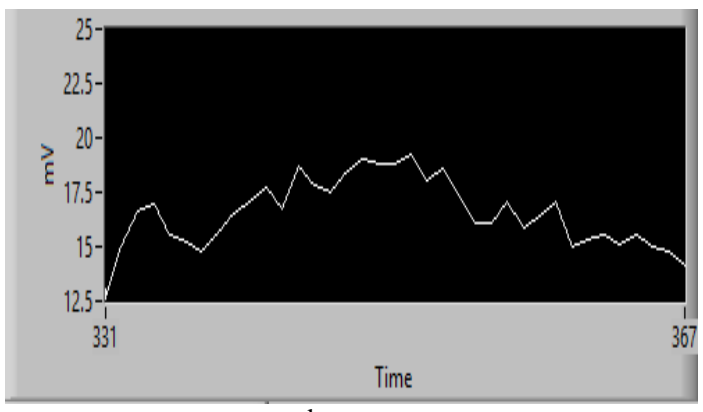

Figure 10: $2^{\text {nd }}$ reading from B11 
C.E Etin-osa et al. / NIPES Journal of Science and Technology Research 2(3) 2020 pp. $70-84$

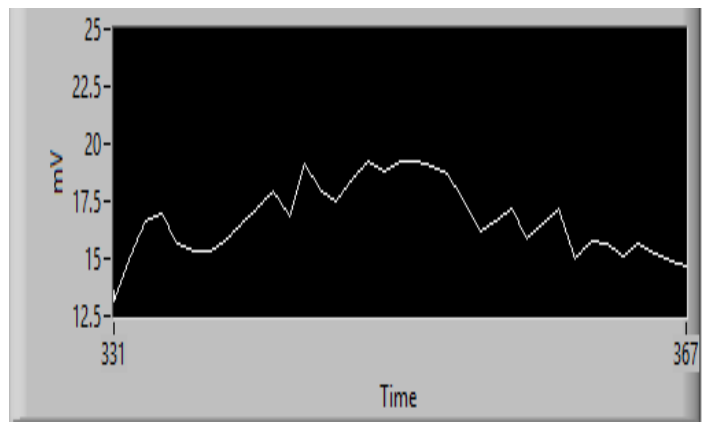

Figure 11: 3rd reading from B11

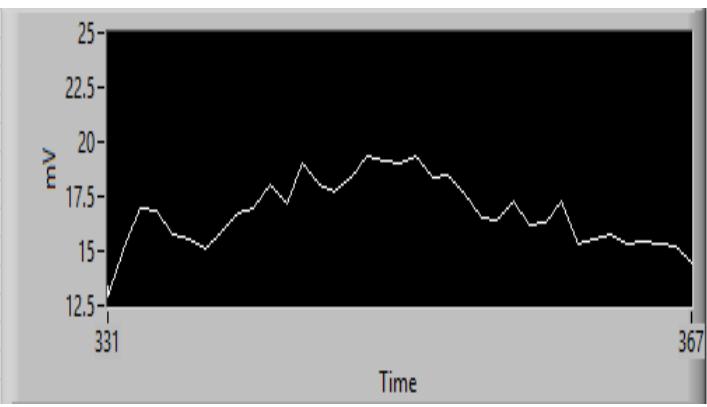

Figure 12: $4^{\text {th }}$ reading from B1

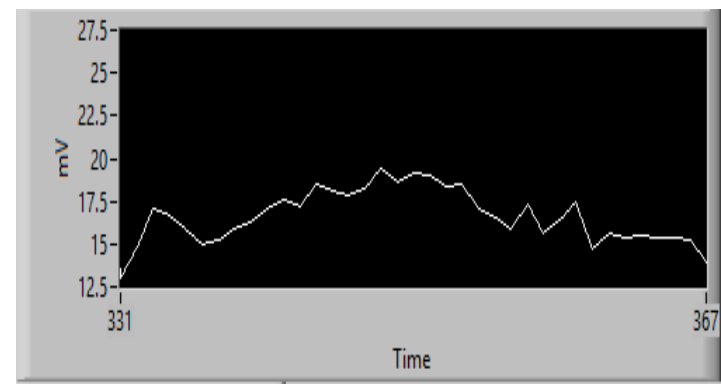

Figure $13: 5^{\text {th }}$ reading from $\mathrm{B} 11$

Table 3: Signal results generated from specimen $\mathrm{B}_{11}$ using the fabricated magnetic device in millivolts

\begin{tabular}{|l|l|l|l|l|l|l|}
\hline \multicolumn{7}{|c|}{ Magnetic Device reading for specimen $\mathrm{B}_{11}$} \\
\hline $\mathrm{S} / \mathrm{N}$ & $\begin{array}{l}\text { 1st } \\
\text { reading } \\
\mathrm{mV}\end{array}$ & $\begin{array}{l}\text { 2nd } \\
\text { reading } \\
\mathrm{mV}\end{array}$ & $\begin{array}{l}\text { 3rd } \\
\text { reading } \\
\mathrm{mV}\end{array}$ & $\begin{array}{l}\text { 4th } \\
\text { reading } \\
\mathrm{mV}\end{array}$ & $\begin{array}{l}\text { 5th } \\
\text { reading } \\
\mathrm{mV}\end{array}$ & $\begin{array}{l}\text { Simufact } \\
\text { reading } \\
\mathrm{N} / \mathrm{mm}^{2}\end{array}$ \\
\hline 1 & 12.95 & 13.1501 & 12.6489 & 12.849 & 13.0501 & 0 \\
\hline 2 & 15.1971 & 15.095 & 15.0261 & 14.894 & 14.8255 & 0 \\
\hline 3 & 16.9532 & 16.6531 & 16.6521 & 17.0624 & 17.0533 & 0.1 \\
\hline 4 & 16.7997 & 16.9998 & 16.9309 & 17.131 & 16.7303 & 0.1 \\
\hline 5 & 15.7911 & 15.689 & 15.49 & 15.488 & 15.8912 & 0.2 \\
\hline 6 & 15.5948 & 15.2947 & 15.2258 & 15.4259 & 15.0252 & 0.4 \\
\hline 7 & 15.0768 & 15.2769 & 14.7757 & 15.0759 & 15.1769 & 0.7 \\
\hline 8 & 15.8554 & 15.7533 & 15.6844 & 15.9646 & 15.9555 & 1.7 \\
\hline 9 & 16.7733 & 16.4732 & 16.4722 & 16.6723 & 16.2716 & 3.1 \\
\hline 10 & 16.9787 & 17.1788 & 17.1099 & 16.9778 & 17.0788 & 6 \\
\hline 11 & 18.0628 & 17.9607 & 17.7617 & 17.9618 & 17.5611 & 10.7 \\
\hline
\end{tabular}


C.E Etin-osa et al. / NIPES Journal of Science and Technology Research 2(3) 2020 pp. $70-84$

\begin{tabular}{|l|l|l|l|l|l|l|}
\hline 12 & 17.1557 & 16.8556 & 16.7867 & 16.6546 & 17.2558 & 18.2 \\
\hline 13 & 18.9685 & 19.1686 & 18.6674 & 19.0777 & 18.4668 & 31.4 \\
\hline 14 & 18.0254 & 17.9233 & 17.8544 & 18.0545 & 18.1255 & 54 \\
\hline 15 & 17.7502 & 17.4501 & 17.4491 & 17.2491 & 17.8503 & 74.1 \\
\hline 16 & 18.3294 & 18.5295 & 18.4606 & 18.6607 & 18.26 & 94.1 \\
\hline 17 & 19.3058 & 19.2037 & 19.0047 & 19.0027 & 19.4059 & 121.3 \\
\hline 18 & 19.1585 & 18.8584 & 18.7895 & 19.2677 & 18.5889 & 129.2 \\
\hline 19 & 19.0515 & 19.2516 & 18.7504 & 18.9505 & 19.1516 & 149.1 \\
\hline 20 & 19.358 & 19.2559 & 19.187 & 19.0549 & 18.9864 & 140.9 \\
\hline 21 & 18.3155 & 19.0154 & 18.0144 & 18.2145 & 18.4156 & 127.7 \\
\hline 22 & 18.4627 & 18.6628 & 18.5939 & 18.4618 & 18.5628 & 109.9 \\
\hline 23 & 17.5904 & 17.4883 & 17.2893 & 17.6996 & 17.0887 & 83.5 \\
\hline 24 & 16.5015 & 16.2014 & 16.1325 & 16.3326 & 16.6016 & 64.9 \\
\hline 25 & 16.4052 & 16.6053 & 16.1041 & 16.4043 & 15.9035 & 42.1 \\
\hline 26 & 17.2461 & 17.144 & 17.0751 & 17.2752 & 17.3462 & 25.3 \\
\hline 27 & 16.177 & 15.8769 & 15.8759 & 15.6759 & 15.6753 & 14.5 \\
\hline 28 & 16.2796 & 16.4797 & 16.4108 & 16.3888 & 16.3797 & 8.5 \\
\hline 29 & 17.3237 & 17.2216 & 17.0226 & 17.2227 & 17.4238 & 4.4 \\
\hline 30 & 15.3248 & 15.0247 & 14.9558 & 14.8237 & 14.7552 & 2.3 \\
\hline 31 & 15.5936 & 15.7937 & 15.2925 & 15.4926 & 15.6937 & 1.2 \\
\hline 32 & 15.7148 & 15.6127 & 15.5438 & 15.4117 & 15.3432 & 0.6 \\
\hline 33 & 15.3768 & 15.0767 & 15.0757 & 15.486 & 15.4769 & 0.3 \\
\hline 34 & 15.4212 & 15.6213 & 15.5524 & 15.7525 & 15.3518 & 0.2 \\
\hline 35 & 15.2856 & 15.1835 & 14.9845 & 14.9825 & 15.3857 & 0.1 \\
\hline 36 & 15.1853 & 14.8852 & 14.8163 & 15.0164 & 15.2854 & 0 \\
\hline 37 & 14.4525 & 14.6526 & 14.1514 & 14.4516 & 13.9508 & 0 \\
\hline & & & & & & \\
\hline
\end{tabular}

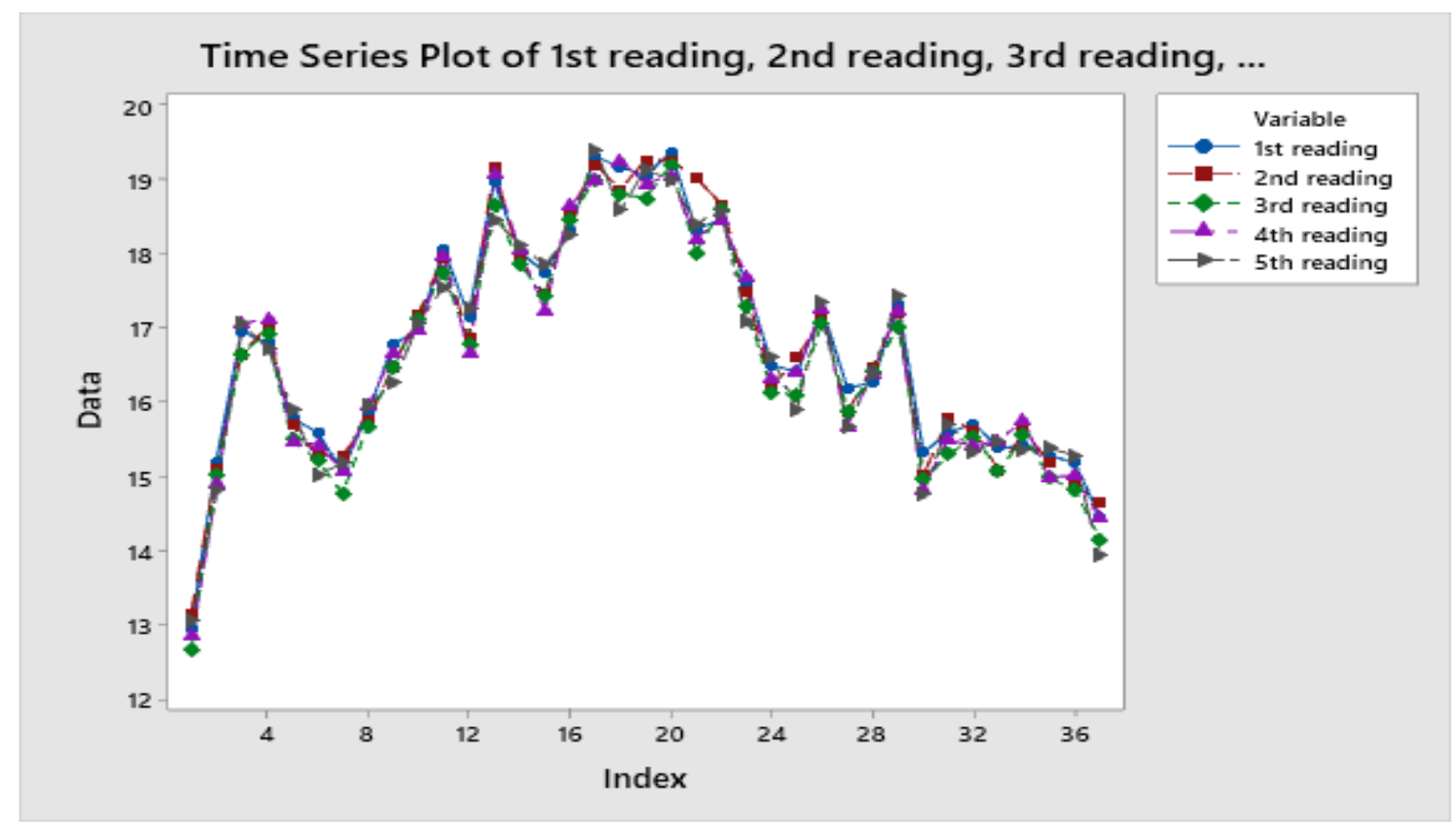

Figure 14: Time series plot of combined reading for $\mathrm{B}_{11}$ 
The yield stresses on the surface of the simulated material in Figure 15 is given a default colour of dark red across the surface of the material before weld. During weld, this material yield stresses of $307.3 \mathrm{~N} / \mathrm{mm}^{2}$ becomes affected due to heat input from the weld source. Different colours symbolizes the extent of yield on the material as it undergoes plastic deformation due to heat input, the dark blue region presented in Figure 16 shows the area mostly affected during the welding process.

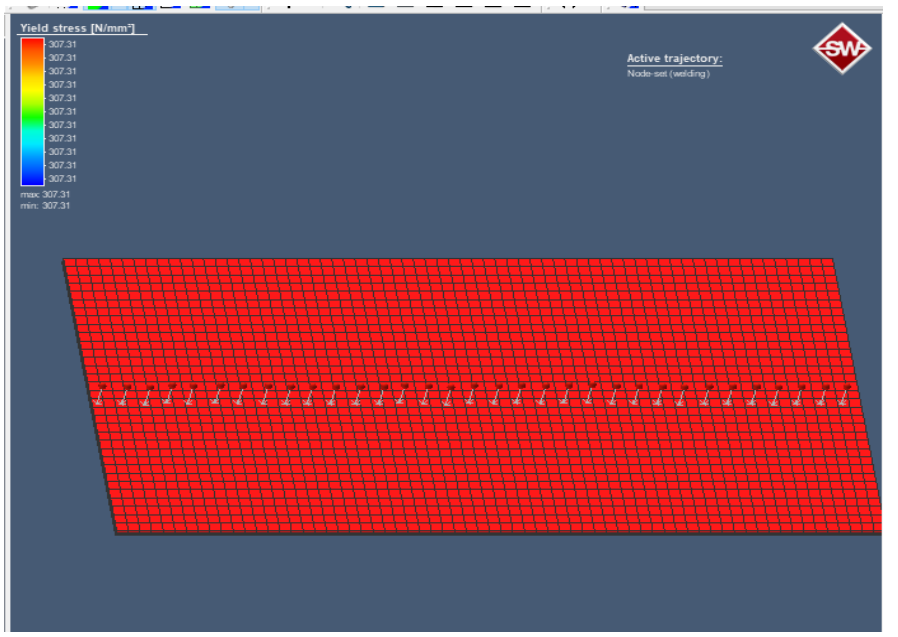

Figure 15: Yield stresses before welding of specimen $B_{11}$

The yield point is the point on a stress-strain curve that indicates the limit of elastic behavior and the beginning plastic behavior. Prior to the yield point, the material will deform elastically and will return to its original shape when the applied stress is removed. Residual stresses arise whenever a component is stressed beyond its elastic limit and plastic deformation occurs. Plastic deformation occurs when the stress exceeds a metal's yield strength. In this research, the difference between yield stress before and after weld was taken as the amount of residual stress in the material. This was achieved by subtracting the yield stress after weld from the yield stress before weld. The area with yield stress of $158.2 \mathrm{~N} / \mathrm{mm}^{2}$ implies that it has accumulated residual stress of $149.1 \mathrm{~N} / \mathrm{mm}^{2}$.

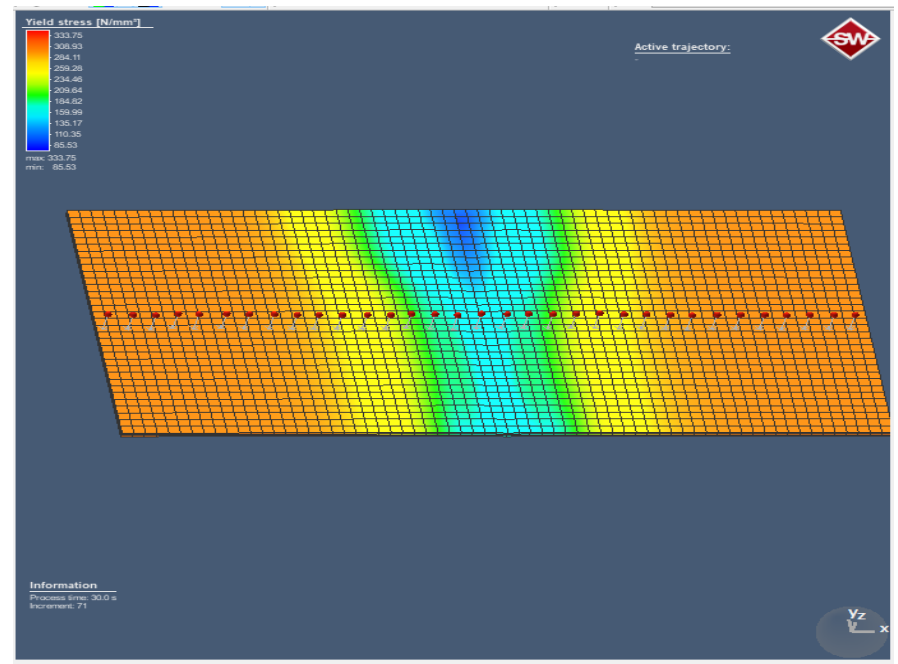

Fig. 16: Yield stresses after welding of specimen $B_{11}$ 
The residual stress developed due to the weld activity is presented in Figure 17

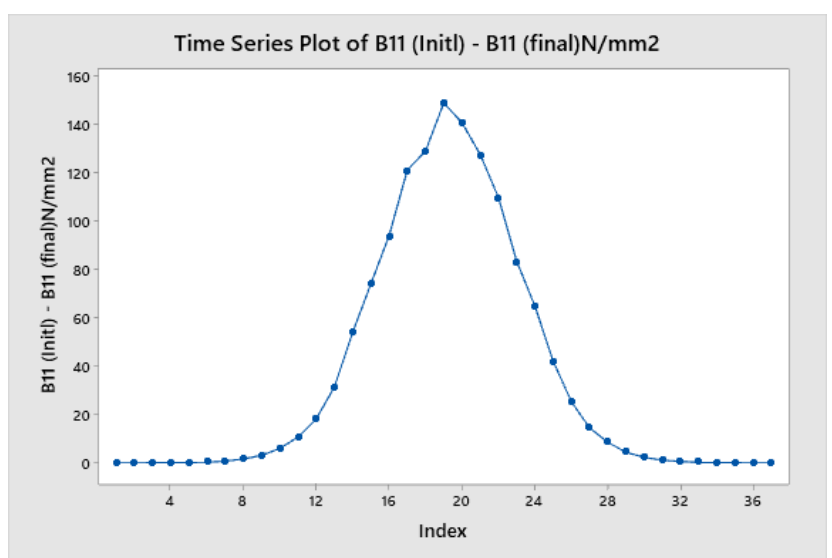

Figure 17: Residual stress plot for specimen $\mathrm{B}_{11}$

Correlation is a statistical tool that is used to show how strongly pairs of variables are related. We applied this statistical tool to measure how strong the relationships are between the 1st up to the 5th experiment and Simufact.weld. Positive correlations were observed from the scatter plot presented in Figure 18, which shows a good agreement of experimental and simulated.

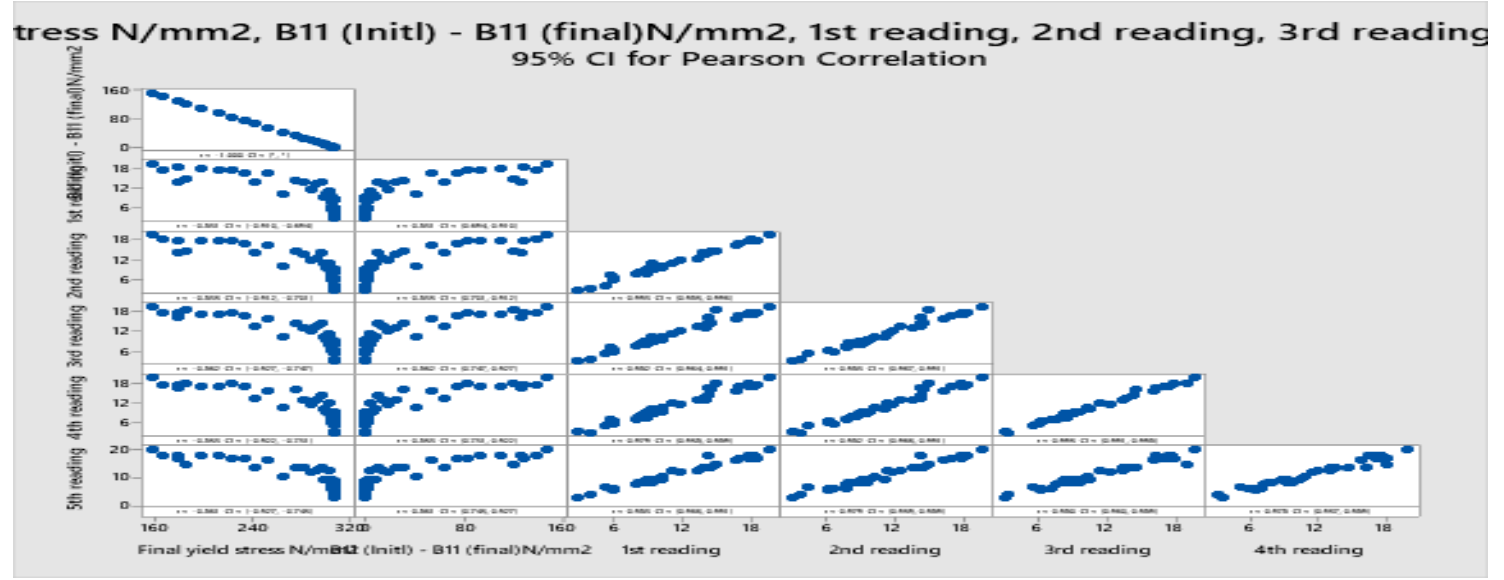

Figure 18: Correlation matrix for $\mathrm{B}_{11}$ experimental and simulated

For this analysis, Table 4 shows the correlation summary of five (5) signals and the simufact reading. Strong positive relationship was observed for all signals generated. The lowest correlation of 0.831 was observed between $1^{\text {st }}$ and the Simufact.weld which implies a strong correlation.

A quadratic model was used for our fitted line plot as presented in Figure 19 which contains curvature. 
For P-value greater than alpha level, the association is regarded as not statistically significant. The equation for Regression Analysis for the $1^{\text {st }}$ reading $(y)$ versus Simufact.weld $(x)$ result is presented in equation 4 . The results presented in table 6 and 7 shows the p-value for $\mathrm{B}_{11}$ to be 0.0071 , which is less than the significance level of 0.05 . These results indicate that the association between the experimental and simulated (Simufact.welding) is statistically significant.

Table 4: Correlations Matrix for $\mathrm{B}_{11}$ Experimental and Simufact.weld

\begin{tabular}{|l|r|r|r|r|r|}
\hline & SMF.W.B11 & reading & $\begin{array}{r}\mathbf{2 n d} \\
\text { reading }\end{array}$ & $\begin{array}{r}\text { 3rd } \\
\text { reading }\end{array}$ & $\begin{array}{r}\text { 4th } \\
\text { reading }\end{array}$ \\
\hline 1st reading & 0.831 & & & & \\
\hline 2nd reading & 0.835 & 0.993 & & & \\
\hline 3rd reading & 0.862 & 0.982 & 0.983 & & \\
\hline 4th reading & 0.853 & 0.979 & 0.982 & 0.995 & \\
\hline 5th reading & 0.861 & 0.983 & 0.979 & 0.980 & 0.978 \\
\hline
\end{tabular}

$$
y=7.774+0.1792 x-0.000806 x^{2}
$$

Table 5 shows the model summary of 2.23562 for s, $77.47 \%$ for coefficient of determination and $76.14 \%$ for the adjusted $\mathrm{R}$ squared where $\mathrm{S}$ represents the average distance that the observed values from the regression line. Most importantly, it shows how wrong the regression model is on average using the units of the response variable. Smaller values are preferable because it indicates that the observations are closer to the fitted line. $\mathrm{R}^{2}$ is regarded as percentage of variation of the response that can be explained by the model. The higher the $\mathrm{R}^{2}$ value, the better the model fits the data. $\mathrm{R}^{2}$ is always between $0 \%$ and $100 \%$. We used adjusted $\mathrm{R}^{2}$ when we compare models that have different numbers of predictors (Simulated vs experimental). $\mathrm{R}^{2}$ always increases when predictors are added to the model, even when it will not improvement to the model. The adjusted $\mathrm{R}^{2}$ value incorporates the number of predictors in the model analysis to choose a better model.

Table 5: Model Summary

\begin{tabular}{|c|c|c|}
\hline S & R-sq & R-sq(adj) \\
\hline 2.23562 & $77.47 \%$ & $76.14 \%$ \\
\hline
\end{tabular}

Table 6: Analysis of Variance

\begin{tabular}{|c|c|c|c|c|c|}
\hline Source & DF & SS & MS & F & P \\
\hline Regression & 2 & 584.264 & 292.132 & 58.45 & 0.0071 \\
\hline Error & 34 & 169.932 & 4.998 & & \\
\hline Total & 36 & 754.196 & & & \\
\hline
\end{tabular}


Table 7: Sequential Analysis of Variance

\begin{tabular}{|c|c|c|c|c|}
\hline Source & DF & SS & F & P \\
\hline Linear & 1 & 520.844 & 78.12 & 0.007 \\
\hline Quadratic & 1 & 63.420 & 12.69 & 0.001 \\
\hline
\end{tabular}

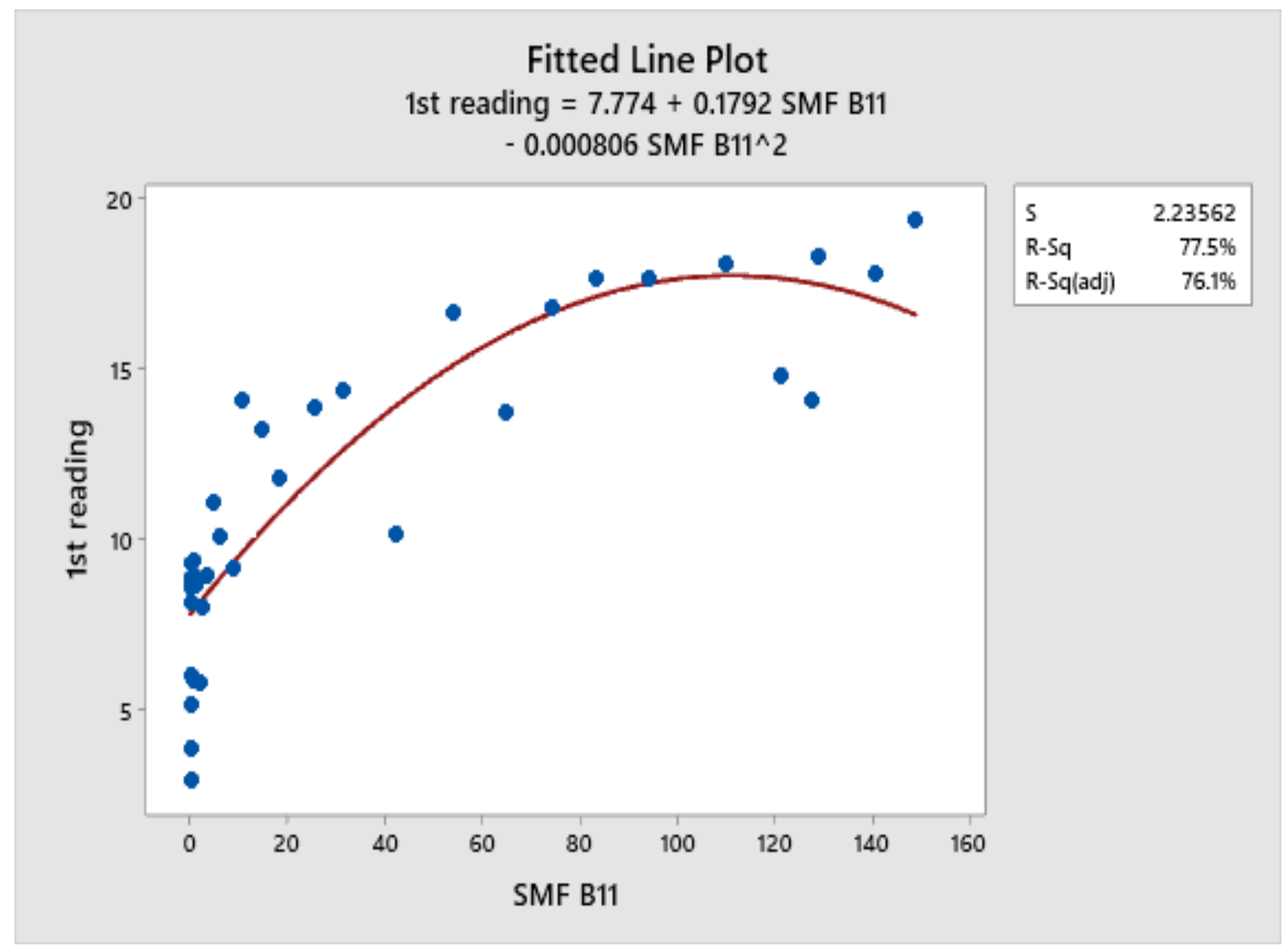

Figure 19: Fitted line plot of $\mathrm{B}_{11}$ simulated

\subsection{Discussion}

The use of magnet to measure residual stress signals has been successfully demonstrated. The Pearson Correlation type was selected for this analysis, it measures the strength and direction of a linear relationship between two variables. The values range from -1 (strong negative relationship) to +1 (strong positive relationship). Values at zero or close to zero implies no or weak relationship/correlation. The lowest correlation between simulated reading vs experimental reading for $\mathrm{B}_{11}$ was found to be 0.831 which indicate a very strong correlation.

Regression analysis was used to determine if the association between the response and each term in the model is statistically significant, and was also applied to determine if the 1st experiments vs Simufact.weld is statistically significant. The p-value obtained was compare to our significance level to assess the null hypothesis. The null hypothesis is that the term's coefficient is equal to zero, which indicates that there is no association between the term and the response. A significance level of 0.05 was selected. A significance level of 0.05 indicates a $5 \%$ risk of concluding that an association exists when there is no actual association. The P-value less than the alpha level shows the association to be statistically significant, and we can conclude that there is a statistically 
significant association between the response variable and the term. For regression analysis, $\mathrm{S}$ is the average distance from the regression line. It was observed that the regression model developed for $\mathrm{B}_{11}$ simulation vs experimental had $\mathrm{S}$ values of 2.23562. Coefficient of determination $\left(\mathrm{R}^{2}\right)$ values of $77.47 \%$ for $B_{11}$. Adjusted $R^{2}$ values of $76.14 \%$ for $B_{11}$ for each simulated reading vs $1^{\text {st }}$ experiments model. Comparing the readings from the device to the simulated value, it was observed that there was a good agreement between the experimental and the simulated result.

\section{Conclusion}

A promising simple and effective residual stress measuring option, locally fabricated has been successfully demonstrated. Comparing its results with that obtained from simulated means, we obtained $\mathrm{R}^{2}$ of $77.47 \%$ with a strong correlation of 0.831 . It had a P-value of 0.0071 which was less than the 0.05 alpha level taken. This device can be adopted in weld residual stress measurement by artisan and roadside welders for effective minimization of residual stress and failures associated with it.

\section{References}

[1] Akande B.F., Debo-Saiye B., Akinjobi S.D., Alao T.O. and Akinrogunde O.O (2016). Causes, Effects and Remedies to the incessant Building Collapse in Lagos State, Nigeria. International Journal of Basic \& Applied Sciences IJBAS-IJENS Vol: 16 No: 04. Pp: 15-30.

[2] Etin-Osa D, Etin-Osa C.E. (2019). "Forensic Science and the Nigerian Society". Journal of Nuclear Sciences, p-ISSN: 2147-7736, e-ISSN:2148-3981, Available electronically at http:// jns.ankara.edu.tr

[3] Simpson, P.M. (1985): Residual stress analysis of type 304 austenitic stainless steel pipe weldments. Presented at the International Conf. of Exposition on Fatigue, Corrosion, Cracking, Fracture Mechanics Failure Analysis." 1985, Salt Lake City, USA.

[4] Olabi, A.G., Hashmi, M.S.J (1995): The effect of post-weld heat-treatment on mechanical- properties and residual-stresses mapping in welded structural steel. J Material Process Technology; 55:117-22.

[5] Elgueder J, L. Roucoules, b, E. Rouhaud, c, F. Cochennec. (2011). Integration of residual stresses in the design of mechanical parts. Materials Science Forum Vol. 681 pp 255-260. https://www.scientific.net/MSF.681.255.

[6] Withers P. J and H. K. D. H. Bhadeshia. X Residual stress: Part 1-Measurement techniques. Materials Science and Technology. (2014) 17(4): 355-365.

[7] Hamfelt Jesper (2015). Evaluation of a New Barkhausen Noise Sensor. Luleå University of Technology Department of Computer Science, Electrical and Space Engineering. Available electronically at http://www.diva-portal.org/smash/record.jsf?pid=diva2\%3A1021486\&dswid=-8335 Accessed on june, 2017

[8] Tomkowski. R, Jonsson .S, Lundin .P, and Nerman .P. (2017) Penetration depth investigation of Barkhausen noise signal for case-hardened components. Conference: 12th International Conference on Barkhasuen Noise and Micromagnetic TestingAt: Fraunhofer Institute for Ceramic Technologies and Systems IKTS, Dresden, GermanyVolume: ISBN 978-952-68852-0-9 